\title{
MULTIPHYSICS MODELLING OF A HYBRID MAGNETIC BEARING (HMB) FOR CALCULATING POWER LOSS AND TEMPERATURE WITH DIFFERENT LOSS MINIMIZATION STRATEGIES
}

\author{
T. Santra ${ }^{1 *}$, D. Roy ${ }^{1}$, A. B. Choudhury ${ }^{1}$, S. Yamada ${ }^{2}$ \\ ${ }^{1}$ Indian Institute of Engineering Science \& Technology, Shibpur, Howrah, India \\ ${ }^{2}$ Division of Biological Measurement and Application, Institute of Nature and Environmental \\ Technology, Kanazawa University, Japan
}

\begin{abstract}
This paper represents a multiphysics modelling for calculating loss and temperature of a hybrid magnetic bearing (HMB) using finite element method (FEM). It also addresses the different loss minimization strategies for the HMB. The main sources of losses are identified as eddy current loss in permanent magnets, flywheel and copper loss in electromagnet. Due to these losses, the temperature distribution in different portions of HMB is computed using coupled field analysis. To minimize the eddy current loss, slits are fabricated in flywheel plate instead of a solid flywheel. The improvement of the control current is investigated by providing a coating of different metal, like copper, brass and stainless steel on the flywheel. A zero bias current (ZBC) scheme has been introduced where no bias current is required to levitate the rotor or to avoid singularity due to external disturbances, thus reducing the copper loss.
\end{abstract}

Keywords: Hybrid magnetic bearing, multiphysics modelling, loss, temperature

*Corresponding author: Tapan Santra (tapan_santra98@,yahoo.co.in)

\section{INTRODUCTION}

Now a day's magnetic bearing is very popular due to its contact free operation, zero lubrication, high rotational speed and almost maintenance free operation [1]. There are different type of configurations: active magnetic bearing [2], passive magnetic bearing $[3,4]$ and hybrid magnetic bearing [5, 6]. In active magnetic bearing the rotor mass is supported by the controlled electromagnets whereas passive magnetic bearing consists of permanent magnets only in attractive or repulsive mode. A hybrid bearing consists of electromagnets and passive magnets both to incorporate the advantages of active and passive bearing in a single Construction. Though magnetic bearing has a lot of advantages, but in most of the times magnetic bearing incurs a high power loss, especially in active magnetic bearing. Passive magnetic bearing has less power loss, but they suffer from low load carrying capacity and instability. In a HMB power loss is reduced by incorporating permanent magnets along with electromagnets. So power loss calculation in a magnetic bearing is very much essential. In most of the literatures, bearing design and control has been reported; there are very few works which report on the power loss estimation and minimization in a magnetic bearing. Kandil et al.[7] addressed a sliding mode control of a hybrid magnetic bearing for wayside flywheel energy storage Systems. Hou Eryong and Liu Kun [8] developed a radial hybrid magnetic bearing (RHMB), 
which has integration of electromagnet and passive magnets along with continuous working air gaps that reduce the losses of the traditional homopolar structure. Xu Yanliang et al.[8] represented a FEM analysis of a hybrid magnetic bearing where permanent magnet was installed in the rotor. $\mathrm{Li} \mathrm{Ji}$ et al.[10] reported the work on a six-pole heteropolar radial hybrid magnetic bearing (HMB) which is only $13.35 \%$ power consumption of a traditional eight-pole active magnetic bearing with the same load capacity. L. Bakay et al. [11] designed and optimized a radial active magnetic bearings (RAMB) and PM-biased hybrid Radial magnetic bearings (HRMB) for flywheel long term energy storage (LTFES).

Although many works are reported on modelling and control of HMB and a few works on loss calculation and reduction, to the best of the author's knowledge, no work has been reported in the literature on the temperature modelling of a hybrid magnetic bearing (HMB). Mukhopadhyay et al.[12] proposed a single axis controlled repulsive type magnetic bearing which is passively stable in the radial direction by means permanent magnets and axially controlled by a single electromagnet with hollow cylindrical

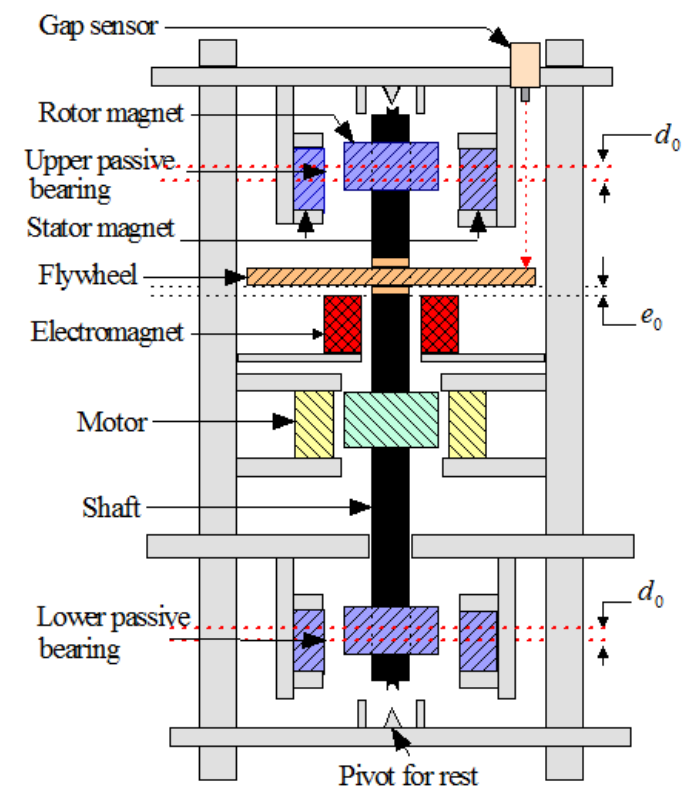

(a)

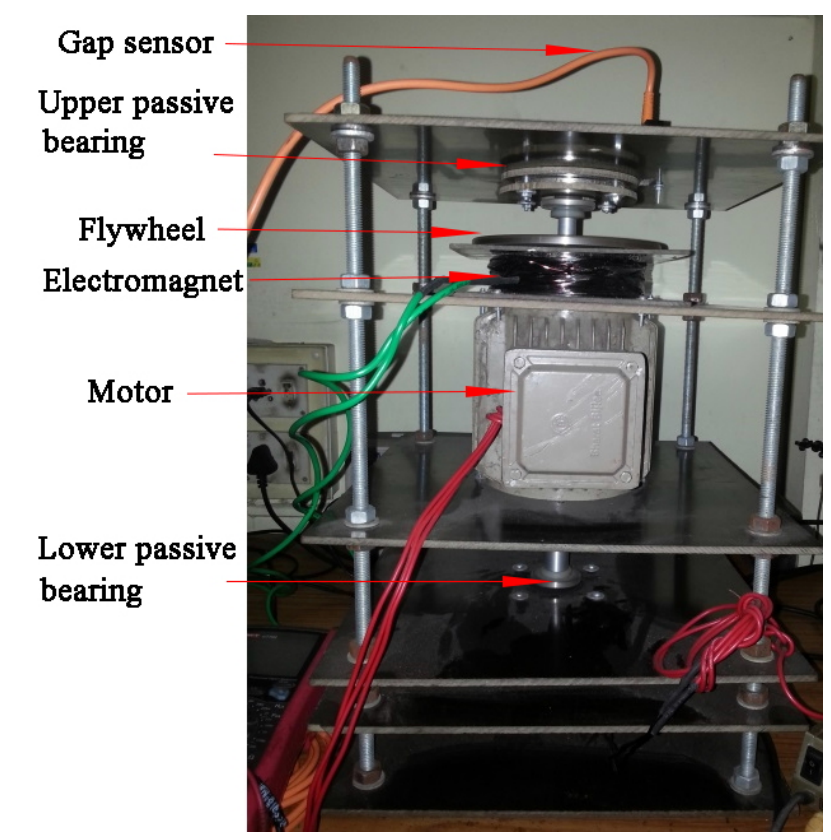

core. So this type of construction is inexpensive. This paper addressed the loss and temperature modelling with different loss minimization strategies for this single axis controlled HMB. Eddy current loss is calculated in passive magnets and flywheel and it is observed that by providing slits in the flywheel eddy current loss can be reduced. With increased rotor speed the eddy current influences the control current which increases the copper loss in electromagnet. It is evident that the most vital loss occurs in HMB is the $i^{2} R$ loss in the electromagnet coil due to the biasing current $\left(\mathrm{i}_{\text {biasing }}\right)$. The biasing current is unavoidable as it is essential to levitate the rotor mass and to avoid singularity when external disturbance comes. A new zero bias current control (ZBC) scheme is developed by modifying the existing configuration of $\mathrm{HMB}$, where bias current is no more required and thus drastically decreases the power loss. After the calculation the loss data from the Maxwell transient setup is transferred to Transient Thermal set-up of ANSYS using the coupled field analysis (CFA). Thus a Multiphysics modelling of HMB has been carried out to couple electromagnetic and thermal.

Figure 1: Construction of a HMB (a) Schematic diagram (b) Fabricated prototype 
Table 1 Dimensions and parameters of the $H M B$

\begin{tabular}{ll}
\hline HMB & Material, Dimensions and Properties \\
\hline Rotor magnet & Material: NdFeB, Ring shaped, Inner dia: $10 \mathrm{~mm}$ Outer dia: $30 \mathrm{~mm}$ Thickness:10 \\
& mm Coercivity $H_{c}=10^{6} \mathrm{~A} / \mathrm{m}$, remanence $B_{r}=1.257 \mathrm{~T}$, density $=0.271 \mathrm{lb} / \mathrm{in}^{3}$, \\
& electrical conductivity $=0.625 \mathrm{MS} / \mathrm{m}$. \\
\hline Stator magnet & Material: NdFeB, Ring shaped, Inner dia: $36 \mathrm{~mm}$, Outer dia: $52 \mathrm{~mm}$, Thickness:10 \\
& mm, Coercivity $H_{c}=10^{6} \mathrm{~A} / \mathrm{m}$, remanence $B_{r}=1.257 \mathrm{~T}$, density $=0.271 \mathrm{lb} / \mathrm{in}^{3}$, \\
& electrical conductivity $=0.625 \mathrm{MS} / \mathrm{m}$ \\
\hline Electromagnet & Core material: Steel, Coil material: Copper, Hollow cylindrical type core, Core \\
& inner dia: $20 \mathrm{~mm}$, Core outer dia: $70 \mathrm{~mm}$, Thickness: $25 \mathrm{~mm}$, Coil inner dia: 70 \\
& $\mathrm{~mm}$, Coil outer dia: $98 \mathrm{~mm}$, Number of turns: $1295 \mathrm{nos}$, Elctro magnet constant \\
& $\mathrm{k}_{\mathrm{e}}=6.65 \times 10^{-4} \mathrm{Nm}^{2} \mathrm{~A}^{-2}$, resistance $\mathrm{R}_{\mathrm{e}}=2.5 \mathrm{~W}$, inductance $L_{e}=0.5 \mathrm{H}$ \\
\hline Flywheel & Material: Stainless steel, Dia: $110 \mathrm{~mm}$, Thickness: $2.5 \mathrm{~mm}$ \\
\hline Rotor & Material: Steel, $4.5 \mathrm{Kg}$ \\
\hline
\end{tabular}
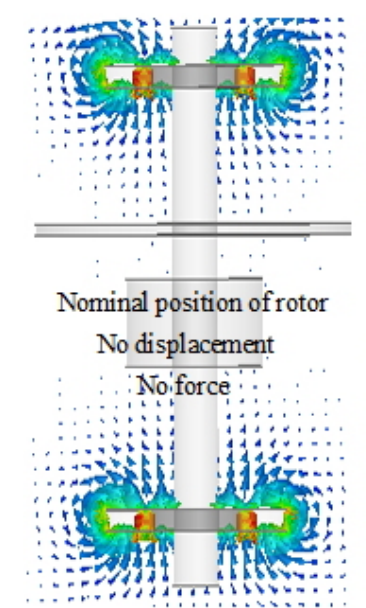

(a)

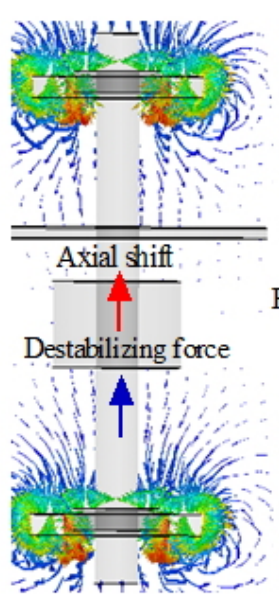

(b)

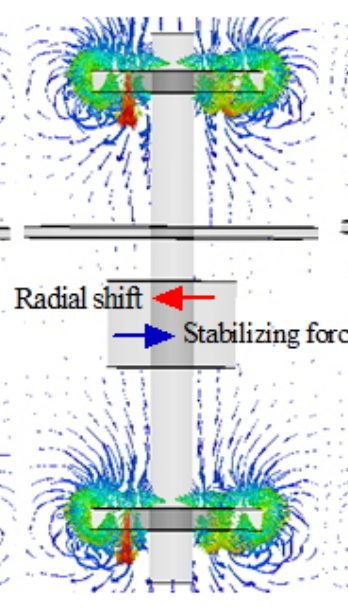

(c)

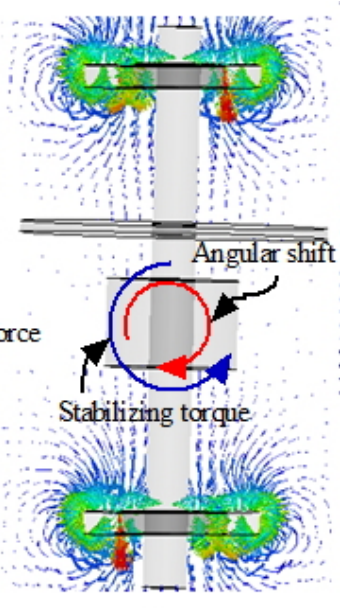

(d)

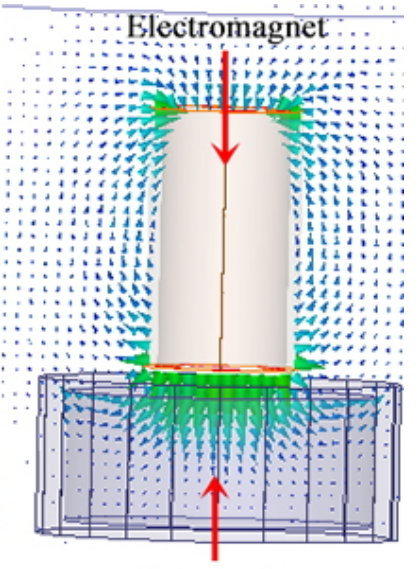

Flywheel

(e)

Figure 2 Magnetic flux density distribution in HMB for different position of rotor (a) Nominal position (b) Axial shift (c) Radial shift (d) angular shift (e) Electromagnet and flywheel

\section{CONSTRUCTION AND WORKING OF HMB}

The objective of a magnetic bearing is to support a rotor and provide stabilization against disturbances in different directions. Figure 1 (a) shows the schematic of a single axis controlled hybrid magnetic bearing. It is composed of two passive bearings at upper and lower part of the shaft and one number hollow cylindrical type electromagnet which attracts a flywheel attached to the shaft. Every passive bearing is consists of two ring magnets, one connected to shaft called rotor magnet and the other is fixed to the machine frame, called the stator magnet. The repulsive force between these two ring magnets makes the system radially stable, but axially unstable due to external disturbances for which rotor magnets get displaced from its nominal concentric position. So to make the rotor axially stable a current controlled electromagnet and flywheel system is incorporated. The attractive force between the electromagnet and flywheel provide the axial stability. An axial offset $d_{0}$ is set to counter balance the rotor weight. Figure 1 (b) shows the fabricated model of the hybrid magnetic bearing for a vertical shaft machine. Here axially polarized $\mathrm{NdFeB}$ ring magnets are used. A Baumer made photoelectric distance 
sensor (OADM 12U6460/S35A) is used to sense the axial displacement of the rotor and feed it back to DSP based controller to control the current in the electromagnet coil accordingly. A LEM make current sensor (LTS 25NP) is used to sense the coil current. The dimension and properties of different components of this HMB are listed in Table 1.

Figure 2 represents the magnetic flux density distribution in passive magnetic system at upper and lower passive bearing for different positions of the rotor: (a) nominal position, (b) axially shifted position, (c) radially shifted position, (d) tilting. It is observed that at different positions of rotor, different type of forces act on the rotor. At the nominal condition, no force, at axially shifted position a destabilizing force, at radially shifted position a stabilizing force, at tilting a restoring torque. It is also observed that in all these cases the flux density distribution is nonuniform in nature, so as the rotor magnet rotates in this magnetic field an eddy current loss will occur. Figure 2 (e) shows for flux density distribution in the electromagnet - flywheel system. So when rotor experiences a radial shift or tilting, eddy current loss will be there in a flywheel.

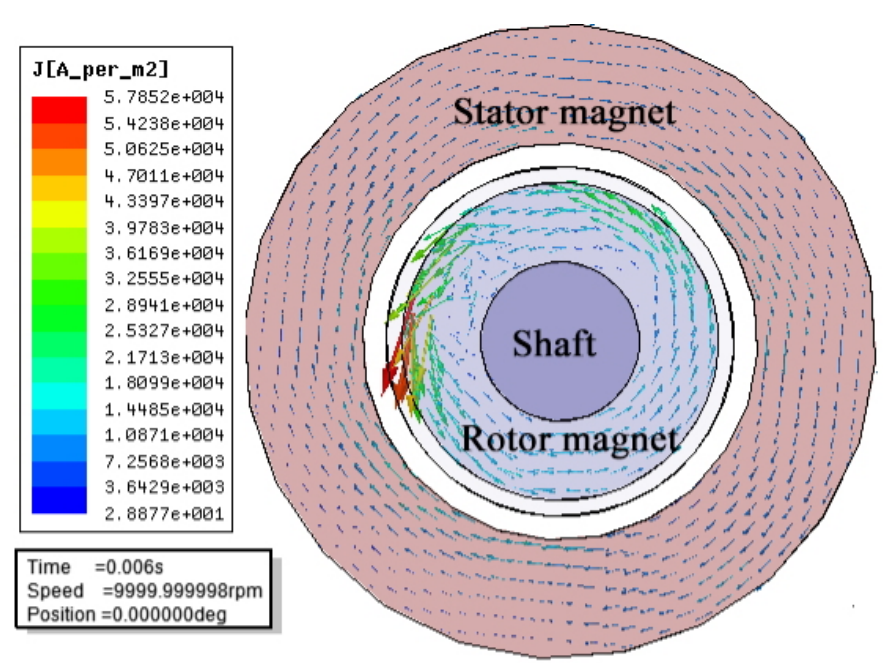

(a)

\section{LOSS CALCULATION MINIMIZATION}

\section{Eddy current loss in permanent magnets}

Figure 2 represents the nonuniform magnetic field for different motions of the rotor. In this nonuniform magnetic field the rotor magnet rotates. So, obviously there will be eddy current loss in the rotor magnet. Though stator magnet is static, but inside it, a permanent magnet (rotor magnet) rotates, so the stator magnet experiences a changing magnetic field and eddy current loss occurs in it also. The rare earth permanent magnets typically have a permeability that is very nearly the same as air over a wide range of applied fields. This fact implies that the magnetization inside the material is fixed, so that the only relevant loss mechanism in the system solely composed of permanent magnets is eddy currents. In this paper the eddy current is calculated by finite element method (FEM) using a transient analysis setup of MAXWELL 3D software. Figure 3 (a) represents the eddy current density vector $(J)$ distribution in stator magnet and rotor magnet both. It is observed that at a particular time the eddy current distribution is not uniform in the magnets and eddy current in the rotor magnet is more than stator magnet.
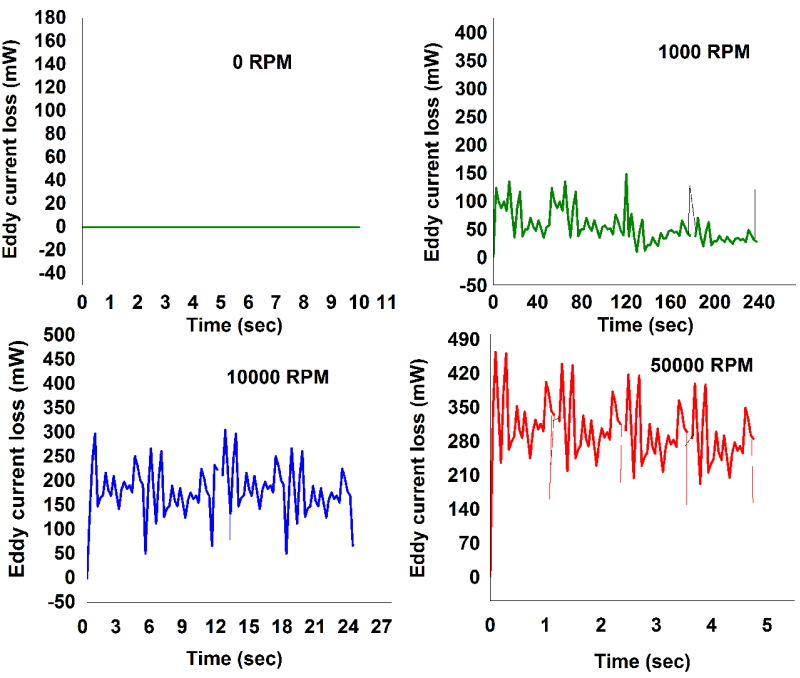

(b)

Figure 3 (a) Eddy current in stator magnet and rotor magnet (b) Eddy current loss in permanent magnets at different rotor speed 


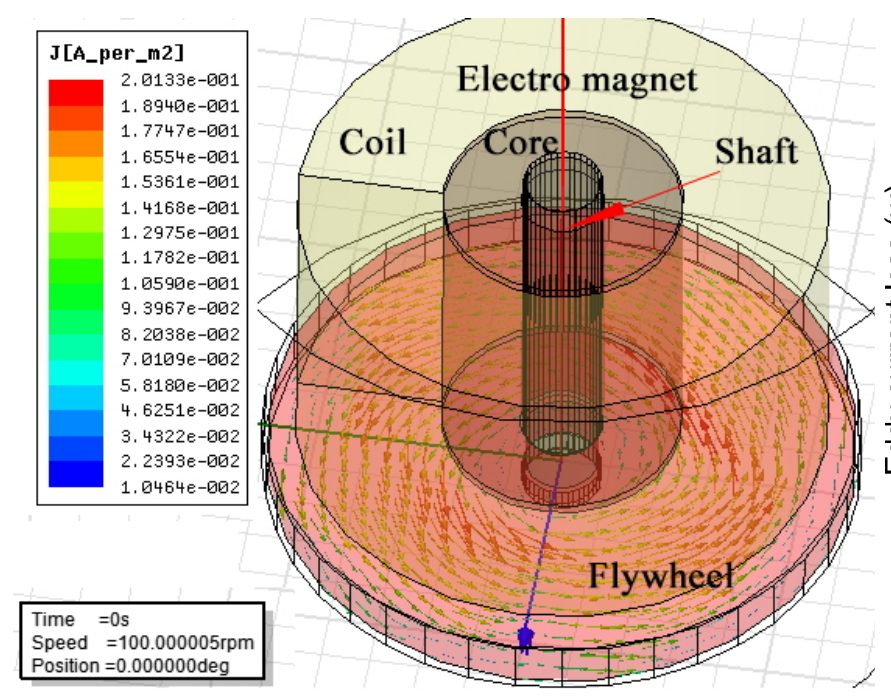

(a)

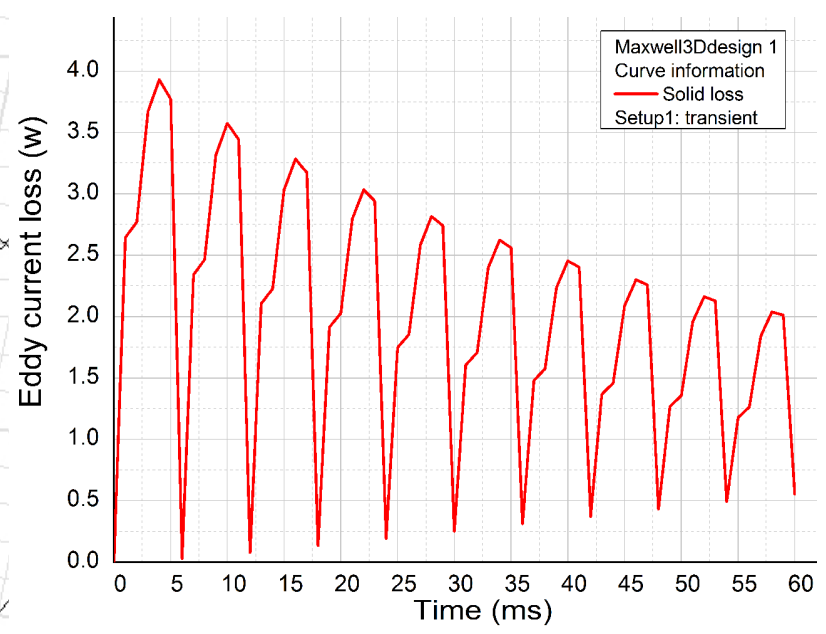

(b)

Figure 4 (a) Eddy current in flywheel plate (b) Transient plot of eddy current loss in flywheel plate with time

Figure 3 (b) represents the eddy current loss in the magnet combination for different speed with respect to time. It is numerically observed that at rotor speed $w=0$, average eddy current $\operatorname{loss} P_{\text {eddy }}=0$, at $w=1000 R P M P_{\text {eddy }}=50 \mathrm{~mW}$, at $w=10000 R P M, P_{e d d y}=200 \mathrm{~mW}$, at $w=$ $50000 R P M, P_{e d d y}=350 \mathrm{~mW}$. It signifies that with the increase in rotor speed eddy current loss in the permanent magnet increases.

\section{Eddy current loss in flywheel}

Figure 2 (e) shows that the flywheel rotates in the magnetic field created by the electromagnet. If the electromagnet is $\mathrm{AC}$ current operated, then certainly there will be eddy current in the flywheel. If the electromagnet is DC current operated then almost a uniform magnetic field is created and as the rotational axis of the flywheel and the axis of electromagnetic field is parallel it seems that no eddy current will be generated. But always the rotor system will have an eccentricity due to rotor mass or due to loading. Then axis of the magnetic field and axis of rotation of the flywheel is not same and eddy current loss occurs in the flywheel. Figure 4 (a) shows the eddy current distribution in the flywheel, obtained from the simulation carried out in the transient analysis setup of MAXWELL 3D software. Figure 4 (b) represents the corresponding eddy current loss with respect to time. It is numerically observed that on average, $2 \mathrm{~W}$ loss incurs in the flywheel by eddy current at 10000 RPM. The eddy current loss in the flywheel can be minimized by providing slits in the flywheel as shown in Figure 5 and Figure 6. It is observed that eight numbers of slits (Figure 5 (a)) in the flywheel reduces the eddy current loss to $150 \mathrm{~mW}$ (Figure 5 (b)) whereas sixteen number of slits incur a loss of $50 \mathrm{~mW}$ (Figure 6 (b)). Thus, by making slits in the flywheel, eddy current loss can be reduced.

\section{Copper loss in electromagnet}

Copper loss in electromagnet occurs as $i^{2} R$ loss in the coil. Coil current mainly composed of biasing current $\left(\mathrm{i}_{\text {biasing }}\right)$ and control current $\left(\mathrm{i}_{\text {control }}\right)$. So to reduce copper loss, both control current and biasing current should be reduced.

\section{Copper loss due to control current}

A transient analysis has been carried out to obtain the electromagnet force for different flywheel speeds. Figure 7 shows the variation of electromagnet force with 


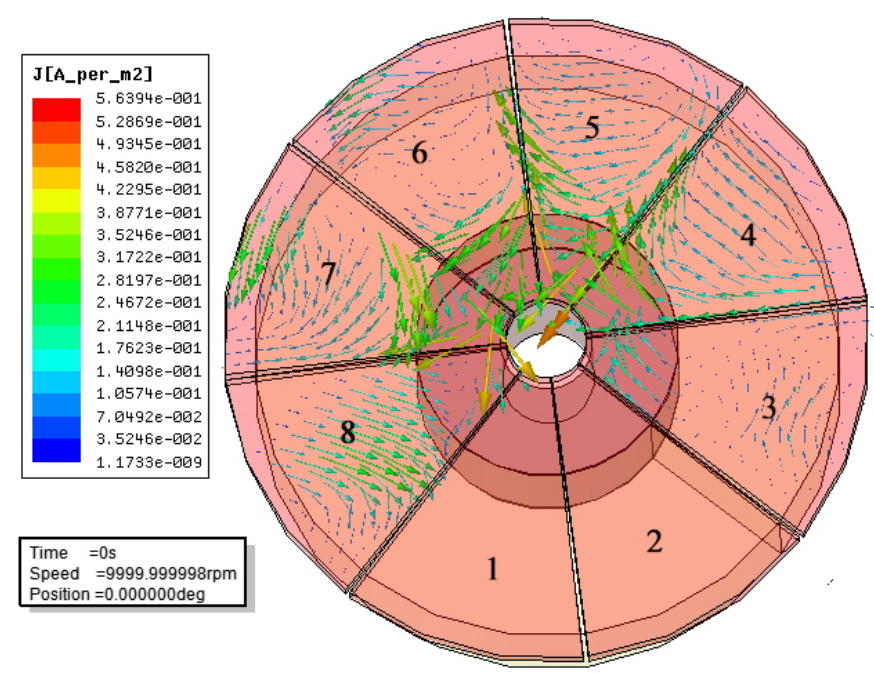

(a)

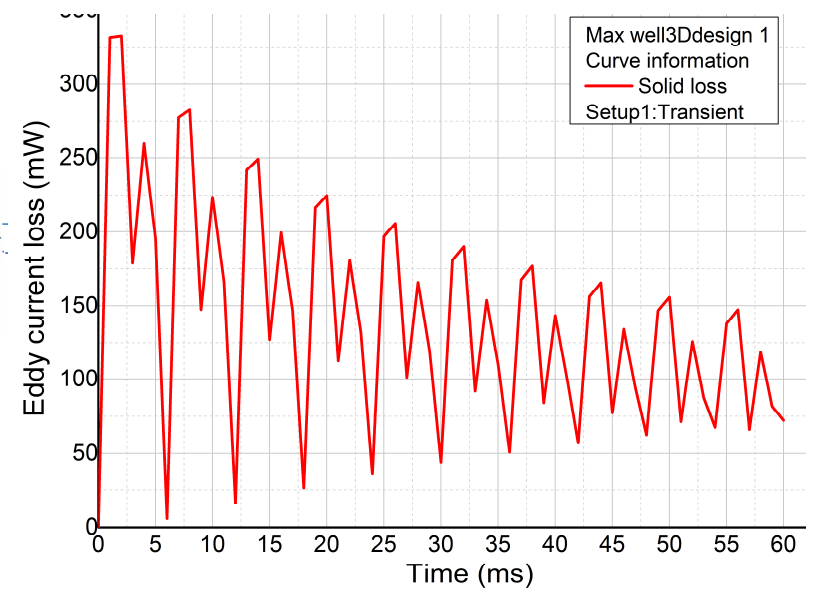

(b)

Figure 5 (a) Eddy current loss in flywheel plate with 8 number of slits (b) Transient plot of eddy current loss in flywheel with 8 numbers of slits

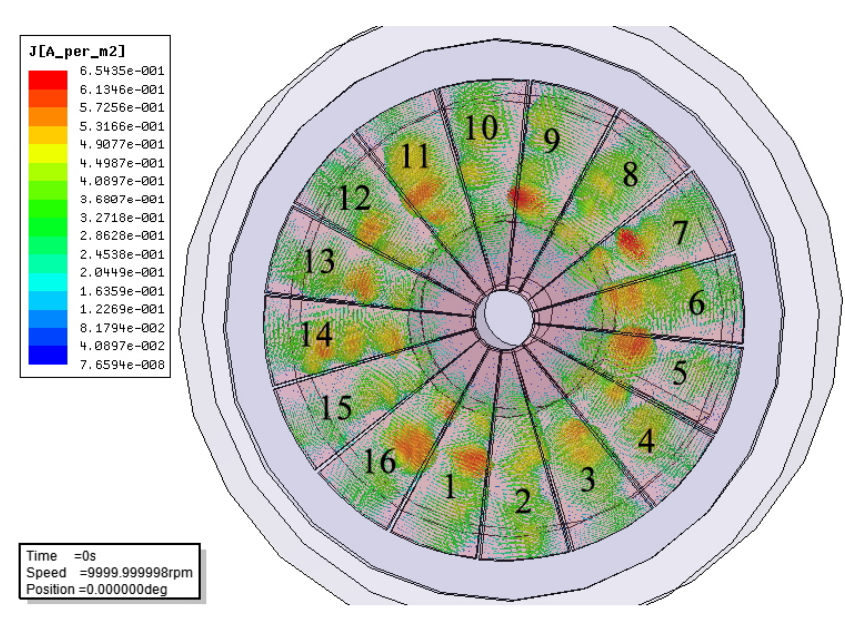

(a)

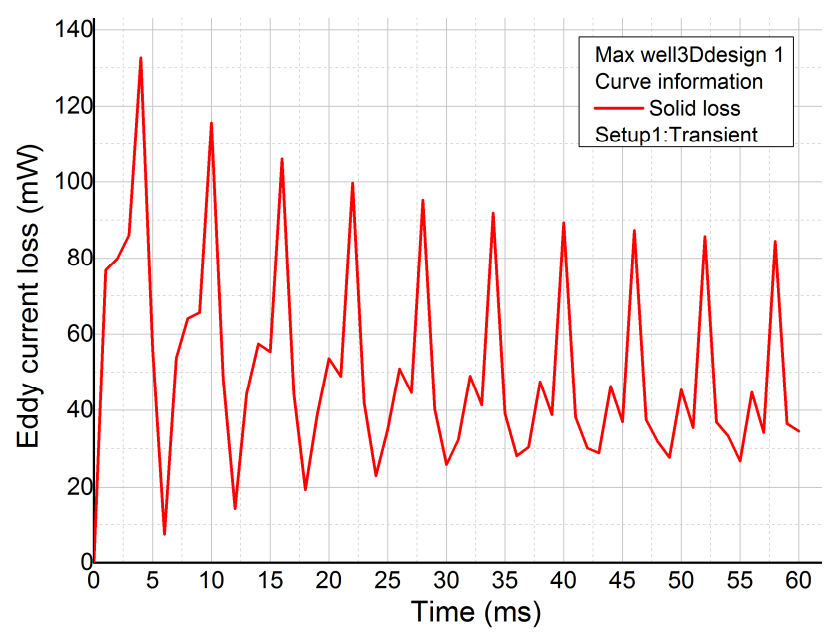

(b)

Figure 6 (a) Eddy current in flywheel plate with 16 numbers of slits (b) Transient plot of eddy current loss in flywheel with 16 numbers of slits

rotor speed. It is numerically observed that force decreases with flywheel speed, but after a certain speed there is no significant change in force. When the flywheel rotates in the electromagnetic field, an eddy current induced in the flywheel. This eddy current generates its own flux which acts opposite to the main flux. A retarding force attempts to slow down the rotor as per Lenz law. This retarding force, $F_{d} \mu f^{2} w$. At low speed, the net flux is comparatively high, increasing $F_{d}$ and power loss. So, the effective magnetic force decreases. At high speed flux decreases more, almost make the force $F_{d}$ constant. So no more extra energy loss, magnetic force remains almost unchanged by speed. Figure 7 also shows that, in HMB the static electromagnetic force $=44.1 \mathrm{~N}$, which is to levitate the $4.5 \mathrm{Kg}$ rotor mass. As the speed increases, force decreases to $42 \mathrm{~N}$ at $3200 \mathrm{RPM}$, after which no significant change in force is observed with speed. As the effective electromagnet force decreases with speed so the control current is to be increased at high rotor speed. 


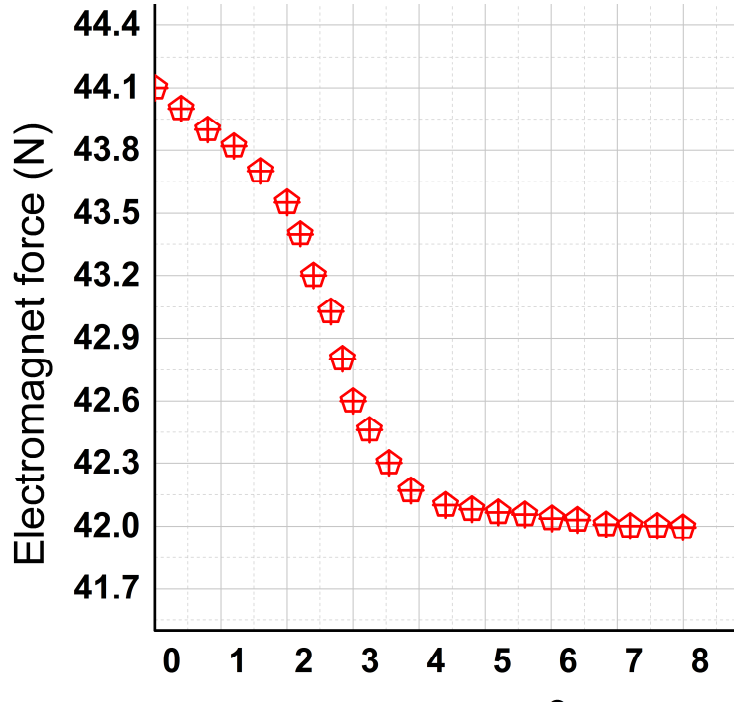

Flywheel speed(x10 ${ }^{3}$ RPM)

Figure 7 Reduction of electromagnetic force with flywheel speed

Figure 8 (a) shows the variation of control current with flywheel speed for different types of metal coating on flywheel plate [13]. It is observed that minimum control current is required for stainless steel and maximum for copper coating. It happens mainly due to difference in eddy current in different metal with different resistivity. Figure 8 (b) represents the variation of control current with the rotor speed for flywheel with different number of slits. It is observed that more the slits in the flywheel, less will be the control current. This also occurs due to the decrease in eddy current for flywheel with slits, but more

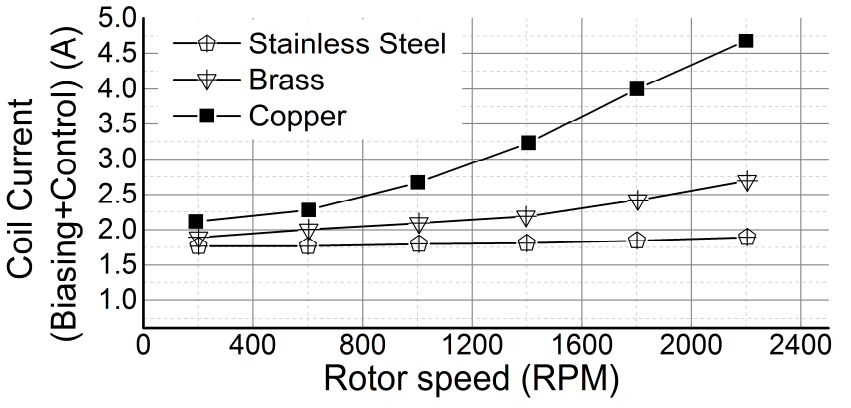

(a) slits may decrease the mechanical strength. There must be an optimum choice of the number of slits. So control current can be minimized by a suitable selection of metal coating on flywheel surface and number of slits in the flywheel.

\section{Copper loss due to biasing current}

The main contribution of copper loss comes from the biasing current, which is required to balance the rotor mass and to avoid singularity due to external disturbances. Figure 9 shows the variation of actual loss in electromagnet in the laboratory. It is experimentally observed that on average a $10 \mathrm{~W}$ loss occurs in electromagnet. A zero bias current control (ZBC) is introduced where no biasing current is required, thus reduces the copper loss. Figure 10 represents the schematic diagram of a ZBC controlled HMB system. In this configuration two electromagnets (electromagnet 1 and electromagnet 2) are used along with two flywheels (flywheel 1 and flywheel 2). The rotor magnet is given an axial offset $x_{0}$ such that the upwards axial force between stator and rotor magnets counter balance the weight of the rotor system. Thus we don't need to use bias current to balance the rotor weight. In this method only one magnet is energized at a time. When the rotor will try to move upward due to an external disturbance,

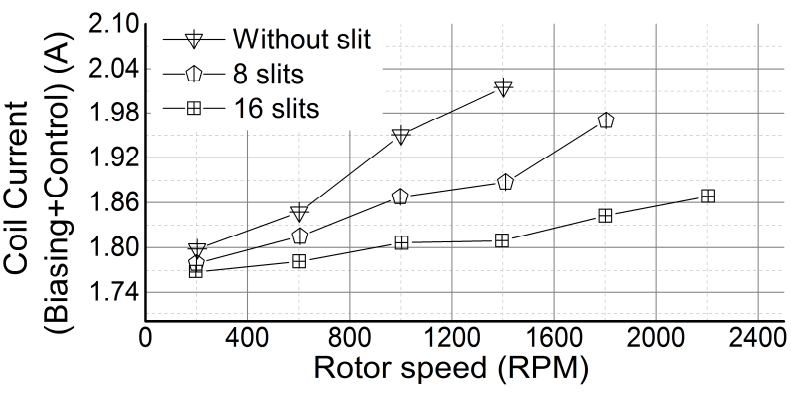

(b)

Figure 8 (a) Variation of electromagnet current with rotor speed for different kinds of metal coating on flywheel (b) Variation of electromagnet current with rotor speed for different number of slits in flywheel 


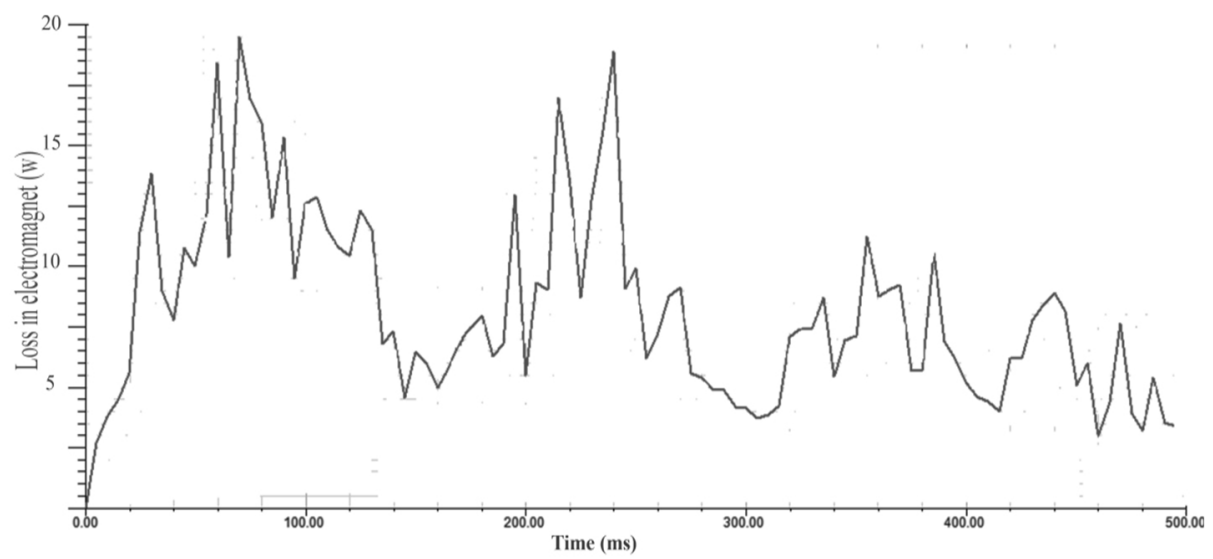

Figure 9 Actual loss in electromagnet from testing

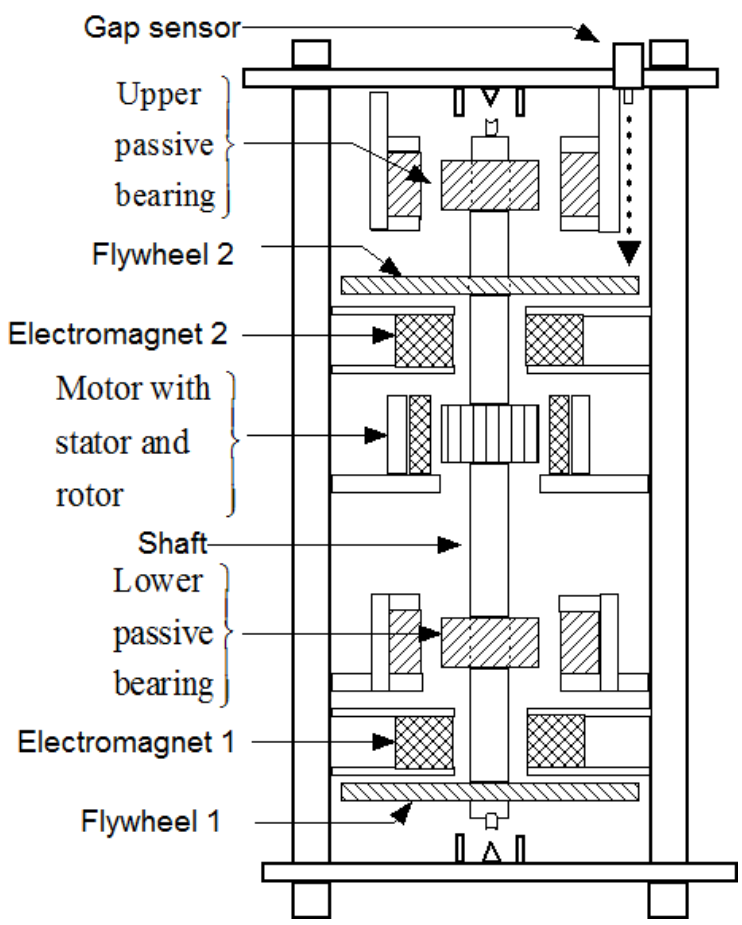

Figure 10 Schematic of ZBC-HMB system

electromagnet-2 will be energized instantaneously and it will attract the flywheel to pull it down, again when the system will try to move downward the upper electromagnet-1 will be energized to pull the flywheel up. Thus the singularity in the system due to external disturbances can be avoided. A sliding mode controller is designed to control the system. A gap sensor senses the axial displacement of the rotor and send a feedback signal to the controller. The controller sends current signals $\left(i_{1}, i_{2}\right)$ to the electromagnets according to the position of the flywheel to set the flywheel in its desired position.

\section{TEMPERATURE MODELLING OF HMB}

The loss calculation of HMB is carried out by FEM using Transient Analysis setup of ANSYS-MAXWELL 3D software as discussed in section 3 . The loss data are transferred to Transient Thermal analysis setup in ANSYS. Figure 11 shows the temperature distribution in different components of HMB. Figure 11(a) shows the thermal distribution and Figure 11 (b) presents the heat flow in stator and rotor permanent magnets respectively. It is observed that the increase in temperature in the stator and rotor permanent magnets is not significant $\left(22^{\circ} \mathrm{C}-22.8^{0} \mathrm{C}\right)$. Naturally the temperature inside the rotor magnet is more than the stator magnet as eddy current in rotor magnet is more than the stator magnet (see Figure 3 (a)). Figure 11 (c) shows the thermal distribution in electromagnet. The maximum temperature is observed in the electromagnet coil due to huge $i^{2} \mathrm{r}$ loss, near about $43^{\circ} \mathrm{C}$ and the steel core temperature is increased about $38^{\circ} \mathrm{C}$. Figure $11(\mathrm{~d})$ represents the thermal distribution inside metal flywheel. No 


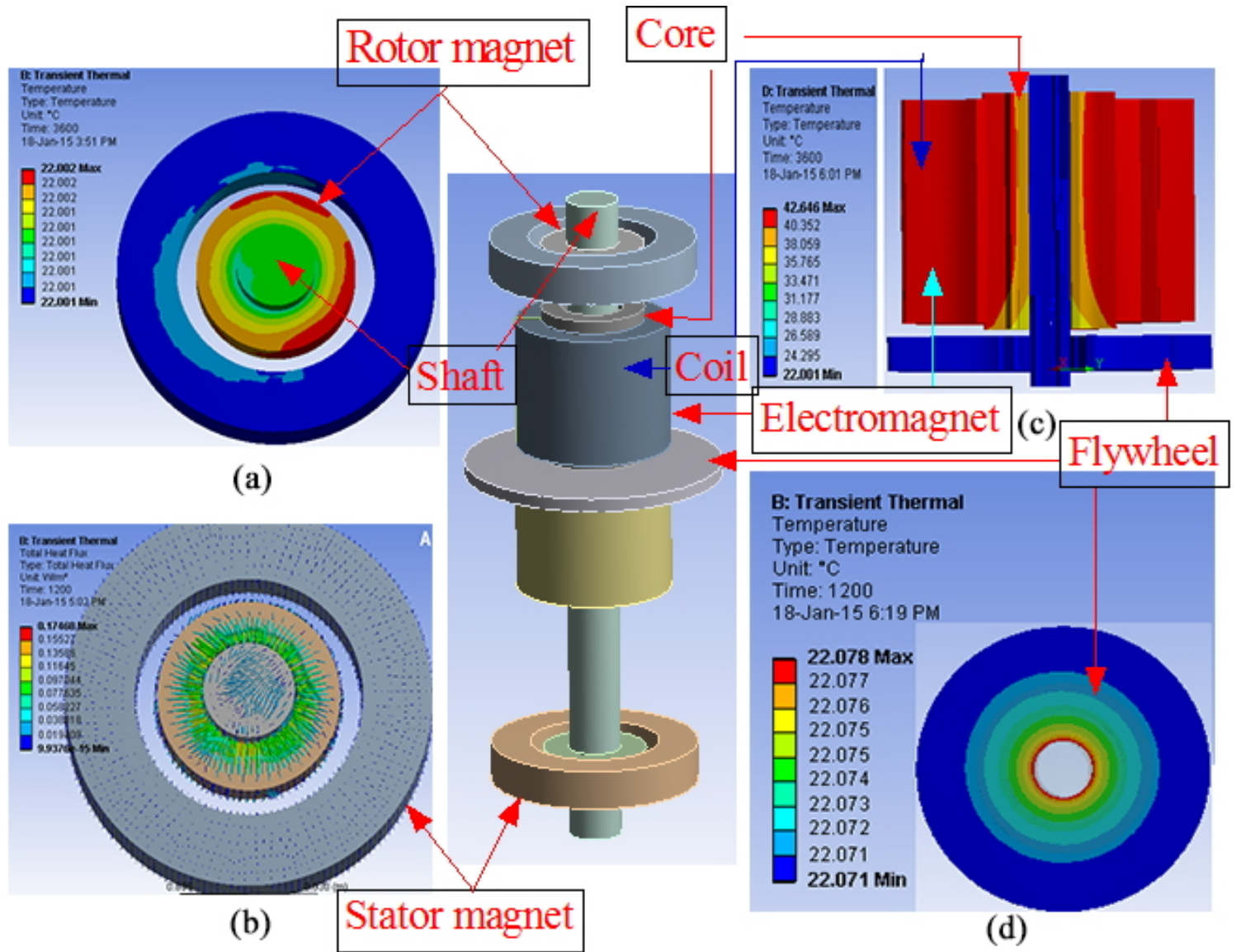

Figure 11 Temperature distribution in different components of HMB (a) stator and rotor permanent magnets (b) Heat flow in stator and rotor permanent magnets (c) Temperature distribution in electromagnet (d) Temperature distribution in flywheel.

significant increase in temperature is noticed, it is near about $22{ }^{\circ} \mathrm{C}-22 \cdot 1^{\circ} \mathrm{C}$. Figure 12 represents the temperature in different components of HMB derived from the lumped parameter model of thermal networks of HMB using numerical methods. The result from the FEM (ANSYS-MAXWELL Thermal transient setup) and numerical method are in close agreement. The experimentally observed temperature of coil are also matches well with the simulated result, as shown in Figure 12 (a).

\section{RESULT AND DISCUSSION}

Table 2 represents the power loss and temperature rise incurred in different components of HMB system. It is observed that almost $97 \%$ reduction in total loss is possible. Mainly the loss is incurred due to high biasing current ( $\mathrm{i}_{\text {biasing }}$ ) in the electromagnet coil because of which maximum temperature rise $\left(43^{0} \mathrm{C}\right)$ is observed in electromagnet coil. Whereas the eddy current losses in permanent magnets and flywheel are not significant and corresponding increase in the temperature also vary less. The loss reduces dramatically by adopting zero bias current control (ZBC) as discussed in section 3.2.2. 
But it requires one more electromagnetflywheel system, more control and driver circuitry which certainly increase the fabrication cost of HMB. Eddy current loss in flywheel decreases with the number of slits in the flywheel but increase in slit reduces the mechanical strength of
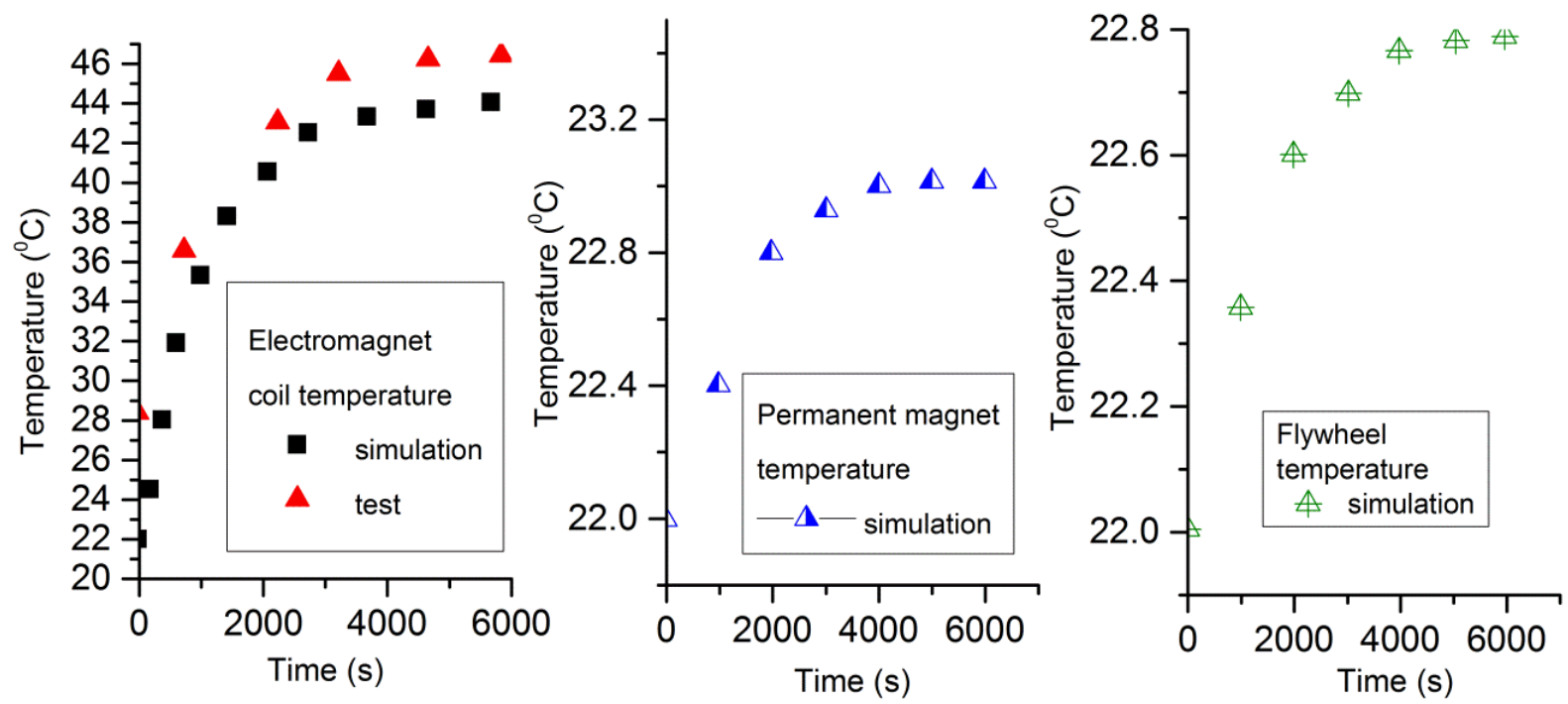

Figure 11 Increase in temperature with time in (a) electromagnet coil (b) Flywheel (c) permanent magnet

Table 2 Reduction of loss after adopting the loss minimization strategies in HMB; * initial temperature is $22^{\circ} \mathrm{C}$

\begin{tabular}{|c|c|c|c|c|c|}
\hline & $\begin{array}{l}\text { Power loss without } \\
\text { minimization efforts } \\
(\mathrm{W})\end{array}$ & $\begin{array}{l}\text { Power loss with } \\
\text { minimization efforts } \\
(\mathrm{W})\end{array}$ & $\begin{array}{l}\text { Loss } \\
\text { reduction }\end{array}$ & $\begin{array}{l}\text { Overall } \\
\text { loss } \\
\text { reduction }\end{array}$ & $\begin{array}{l}\text { Tempe- } \\
\text { rature } \\
\left({ }^{0} \mathrm{C}\right) *\end{array}$ \\
\hline $\begin{array}{l}\text { Permanent } \\
\text { magnets }\end{array}$ & $0.05^{\prime} 2=0.1 \mathrm{~W}$ & $0.05^{\prime} 2=0.1$ & $0 \%$ & \multirow[b]{3}{*}{$97.4 \%$} & 22.8 \\
\hline Flywheel & $2 \mathrm{~W}$ & $0.15 \mathrm{~W}$ for 8 no. slits. & $92.5 \%$ & & 22.1 \\
\hline $\begin{array}{l}\text { Electro- } \\
\text { magnet }\end{array}$ & $\begin{array}{l}\left(\mathrm{i}_{\text {control }}^{2}+\mathrm{i}_{\text {biasing }}^{2}\right)^{\prime} \mathrm{r} \\
=\left(0.14^{2}+1.8^{2}\right) 2.5 \\
=8.149 \mathrm{~W}\end{array}$ & $\begin{array}{l}\left(\mathrm{i}_{\text {control }}^{2}+\mathrm{i}_{\text {biasing }}^{2}\right)^{\prime} \mathrm{r} \\
=\left(0.08^{2}+0.00^{2}\right) 2.5 \\
=0.016 \mathrm{~W}\end{array}$ & $99.8 \%$ & & 43.0 \\
\hline
\end{tabular}

flywheel. So, always there is a trade off between loss reduction and costing.

\section{CONCLUSION}

This paper considers the loss and temperature modelling of a hybrid magnetic bearing (HMB). It also represents the different loss minimization strategies in a HMB system. Eddy current and copper losses are investigated by FEM using
Transient Analysis of MAXWELL 3D software. The loss data is transferred to Transient Thermal setup of ANSYS and temperature distribution in the different components of HMB is calculated. It is observed that eddy current loss can be minimized upto $90 \%$ by adopting two strategies: providing slits in the flywheel and stainless steel coating on the flywheel top surface. This paper proposed a zero bias current $(\mathrm{ZBC})$ control where bias current is 
no more required, thus drastically reduces the copper loss in the electromagnet coil. It is possible to reduce the power loss about $90 \%$ after considering all the loss reduction strategies. It is also observed that maximum temperature appears in electromagnet $\left(43^{\circ} \mathrm{C}\right)$ and there are no significant changes in temperature in flywheel and permanent magnets.

\section{ACKNOWLEDGEMENT}

This research work is sponsored by the Science and Engineering Research Board (SERB), Department of Science \& Technology (DST), New Delhi, India, order number SR/S3/EECE/0164/2012.

\section{REFERENCES}

[1] Fang, J., Le, Y., Sun, J., and Wang, K., Analysis and Design of Passive Magnetic Bearing and Damping System for High-Speed Compressor, IEEE Trans. Magn., 2012, 48 (9), 2528-2537. https://doi.org/10.1109/TMAG.2012.21 $\underline{96443}$

[2] Matsumura, F. and Kodayashi, H., Fundamental Equation for Horizontal Shaft magnetic Bearing and its Control System Design, Journal of Electrical Engineering, Japan, 198,101C(6),137144.

[3] Yonnet, J. P. Passive magnetic bearing with permanent magnets, IEEE Trans. Magn. 1978,14(5), 803-805. https://doi.org/10.1109/TMAG.1978.10 60019

[4] T. Santra, D. Roy and A. B. Choudhury, Calculation of Passive Magnetic Force in a Radial Magnetic Bearing Using General Division Approach, Progress in Electromagnetics Research M, Vol. 54, pp. 91-102, February 2017. https://doi.org/10.2528/PIERM1612060 $\underline{2}$
[5] Haoze Wang, Kun Liu, and Peng Ao, Magnetic Field and Specific Axial Load Capacity of Hybrid Magnetic Bearing, IEEE Trans. Magn., 2013, 49 (8), 4911 4017. https://doi.org/10.1109/TMAG.2013.22 $\underline{48162}$

[6] Tapan Santra, Debabrata Roy, Amalendu B Choudhury and Sotoshi Yamada, Vibration control of a hybrid magnetic bearing using an adaptive sliding mode technique, Journal of Vibration and Control (JVC). https://doi.org/10.1177/1077546317717 $\underline{884}$

[7] Mohamed S. Kandil, Maxime R. Dubois and Joao P. Trovao, A Sliding Mode Control of a Hybrid Magnetic Bearing for Wayside Flywheel Energy Storage Systems, Vehicle Power and Propulsion Conference (VPPC), 2015, IEEE https://doi.org/10.1109/VPPC.2015.735 2883

[8] Hou Eryong and Liu Kun, A Novel Structure for Low-Loss Radial Hybrid Magnetic Bearing, IEEE Trans. Magn., 2011, 47(12), 4725-4733. https://doi.org/10.1109/TMAG.2011.21 60649

[9] Yanliang, Xu, et al., Analysis of Hybrid Magnetic Bearing With a Permanent Magnet in the Rotor by FEM, IEEE Trans. Magn., 2006, 42(4),1363-1366. https://doi.org/10.1109/TMAG.2006.87 1396

[10] Li Ji, Longxiang $\mathrm{Xu}$, and Chaowu Jin, Research on a Low Power Consumption Six-Pole Heteropolar Hybrid Magnetic Bearing, IEEE Trans. Magn., 2013, 49(8), 4918-4926. https://doi.org/10.1109/TMAG.2013.22 $\underline{38678}$

[11] Bakay, L., Dubois, M. and Viarouge, P., Losses in hybrid and active magnetic bearings applied to Long Term Flywheel Energy Storage, Power Electronics, Machines and Drives (PEMD 2010), 5th IET International Conference on, 2010. https://doi.org/10.1049/cp.2010.0067 
T. Santra et al. Multiphysics modelling of a hybrid magnetic bearing (HMB) for calculating power loss and temperature with different loss minimization strategies

[12] Mukhopadhyay, S. C. et al., A New Repulsive Type magnetic Bearing Modeling and Control, IEEE PEDS Conference, Singapore, May 26-29, 1997
[13] Mukhopadhyay, S. C., Modeling of a Repulsive Type Magnetic Bearing for Five Axis Control Under Intermittent Operation Including Eddy Current Effect, Proceedings of the First IEEE International Workshop on Electronic Design, Test and Applications (DELTA.02), 2002,7(02) 